\title{
Methods of sampling and analysis and our concepts of ocean dynamics
}

\author{
PETER J. WANGERSKY \\ Centre for Earth and Ocean Research, University of Victoria, P. O. Box 3055, Stn CSC, Victoria, BC V8W 3P6, Canada. \\ E-mail: wangers@telus.net
}

\begin{abstract}
SUMMARY: In the last two decades, the increase in multi-nation, multi-ship projects has underlined the importance of intercalibration and intercomparison studies. At the same time, it is becoming obvious that with our present methods of sampling and analysis we can never hope to distinguish the variability in our sampling and analysis techniques from the variability in the universe sampled. The presence of discontinuities in many of the quantities measured suggests that our sampling grid, as maintained by oceanographic vessels, is too limited both in space and in time. Some variety of self-reporting sampling buoy is the obvious answer for physical and chemical parameters, although as yet we do not have detectors for many of the quantities of interest. Even with such buoys, it would seem unlikely that we could construct a grid of such buoys tight enough to measure the local variability of the oceans without the buoys themselves contributing to this variability. The limit finally selected for such a sampling grid will probably be some compromise between scientific capability and economic reality.
\end{abstract}

Keywords: intercalibrations, continuous recording, variability, buoys.

RESUMEN: MÉTODOS DE MUESTREO Y ANÁLISIS Y NUESTRO CONCEPTO DE LA DINÁMICA DE LOS OCÉANOS. - En las dos últimas décadas el incremento de los proyectos multi-nacionales, con la utilización de muchos barcos ha subrayado la importancia de inter-calibración y comparación de estudios. Al mismo tiempo es obvio que con los métodos actuales de muestreo y análisis no podemos nunca esperar a distinguir la variabilidad de muestreos y análisis de la variabilidad del universo muestreado. La presencia de discontinuidades en muchas de las cantidades determinadas sugiere que nuestra zona de muestreo, realizada desde buques oceanográficos, es demasiado limitada tanto en espacio como en tiempo. La respuesta a la medida de parámetros físico-químicos seria el tipo de boya capaz de muestrear y adquirir datos, aunque no tenemos detectores para muchas de las cantidades de interés. Incluso con éste tipo de boyas, no parece posible que se puede construir una red lo suficientemente tupida para medir la variabilidad local de los océanos sin que las boyas contribuyan a esta variabilidad. El limite finalmente seleccionado por este tipo de red de muestreo radicará en un compromiso entre la capacidad científica y la realidad económica

Palabras clave: inter-calibración, muestreo continuo, variabilidad, boyas.

\section{INTRODUCTION}

I have been working in science for over half a century now. In that time, the tools of science have changed more than they had in the previous two hundred years. When I began my university studies in chemistry at Brown University, in the summer of 1944 (wartime accelerated program), the science or engineering major could be recognized on sight by the slide rule he carried slung on his belt and the copy of the Chem Rubber math tables in his left hand. Both were indispensable tools, used every day. Adding machines did exist, and some could even be made to multiply, after a fashion. They were strictly mechanical, however, and the wear and tear on various joints, machine and human, 
coupled with the high frequency of random inputs, discouraged us from the use of any but the most necessary statistical tools. Perhaps this is why most analytical chemists of this vintage believe that if one does the analyses right, there's no need for statistics. This is a self-reinforcing fallacy; if you don't do the statistics, you never discover your limitations or the limitations of your methods and the universe you are sampling.

Most of the other tools we used in chemistry, such as our analytical balances and burettes, would have been familiar to scientists of an earlier century. Gravimetric and volumetric analyses were still the standbys of quantitative analysis, and hydrogen sulphide was the all-pervasive odour of qualitative. We still started off our sophomore year in quantitative analysis by calibrating our balance weights, pipettes, and burettes. I think the faculty felt that anyone persistent enough to make it through that exercise without exploding from sheer frustration would probably make it to graduation. Certainly most of the protochemists who switched to Economics did so in that year of their studies. The techniques involved were of little practical use; I have worked in a variety of industrial and research labs, and I have never found one that calibrated either balance weights or volumetric apparatus. It was much more economical - and safer - to buy a better grade of precalibrated equipment.

Colorimetric analysis was known at the time, but much of it was done using the human eye as the color comparator. Some oceanographic laboratories as much as ten years later were still keeping tubes of color standards (sometimes terribly faded) as their fall-back means of measuring phosphate and silicate concentrations in water. Electronic colorimeters did exist; during my first year in the Service, working as a laboratory technician in an Air Corps hospital, I used a Dubosc optical colorimeter for my blood chemistry analyses. Later our laboratory acquired a Leitz electronic colorimeter. In my junior year advanced analytical course, taken in 1948, after my brief sojourn in the U.S. Army Air Corps, I was introduced to a spectrophotometer, the Beckman DU, beloved and bedamned by a generation of analysts, the workhorse of spectrophotometry for the next ten years at least, and possibly twenty. Throughout this period the rate of change in scientific instrumentation was slow, almost glacial.

My first job after graduation from Brown University was as a sea-going chemical technician at the Scripps Institute of Oceanography, in La Jolla, Cal- ifornia. The kinds of analyses run at sea were primitive, at best, which was fortunate, because the conditions under which we had to run these analyses were equally primitive. The one analysis which had to be done with precision, the determination of salinity, was run on shore; on board ship we ran a titrimetric analysis for dissolved oxygen and a colorimetric analysis for phosphate. In the literature there were colorimetric methods for silicate and nitrate, but with only one chemical technician and a station about every four hours, there simply wasn't time to run much more than two kinds of analysis. You might find in the literature the occasional paper on trace metal concentrations, usually the result of a $\mathrm{Ph}$. D. thesis. These methods were seldom followed up, as their authors went off to land-based jobs. This was probably just as well, as in many cases what was really being measured was the level of sampling contamination.

The equipment with which we did these analyses would not have looked out of place on the Challenger on its 1875 voyage. Should Buchanan, the chemist on the Challenger, have visited any of our shipboard laboratories, he would have felt right at home. The oxygens were titrated with a standard laboratory burette. The magnetic stirrer had not yet been invented, so stirring was done by hand. The starch indicator normally went bad before the end of a three-week cruise, so we arranged with the cook to loan us a pot and a potato in the third week. The phosphates were run on a simple colorimeter, but it had not been too long since the standard color tubes and visual comparison had been the usual method. The ships still carried the color tubes, just in case.

The salinities were run at the shore laboratory in Point Loma. A group of female technicians, the salinity girls, ran the Mohr-Knudsen silver nitrate titrations to a chromate endpoint for eight hours a day. Needless to say, there was a considerable turnover in this group. There was always a shortage of salinity girls, and the sample bottles kept coming in from the ships and stacking up in the hallways. I should add that the job of running salinities was not necessarily limited to women; that just happened to be the case during the time I was there. Once the salinity had been determined, then using the protected temperatures the density was found from a huge nomograph, the depth was calculated from the difference between protected and unprotected temperatures, smooth curves were plotted between the salinity, oxygen, and phosphate points so determined, and the standard depths picked off these curves. The 
points actually reported were never real data points, except by accident, but were estimates calculated for standard depths, based on the rule of continuity between real data points.

Perhaps one might have expected this degree of conservative equipping and planning, for it was just after a rather large war, during which little or no scientific equipment not related to the war effort was built. However, little changed in this field over the next dozen years. A major turning-point in marine chemistry was the development of the inductive salinometer (Brown and Hamon, 1961). The determination of salinity was soon fashioned into an instrument which could take these measurements in situ (Brown, 1964), and the age of modern oceanography had begun. The changeover was neither instantaneous nor painless; an account of the earlier methods and of the steps involved in the shift to the inductive method can be found in Grasshoff et al. (1983).

Major contributors in the move to greater analytical instrumentation were the increasing reliability of the transistor and the computer chip. Where in the mid -1950 s a well respected oceanographer had commented that the optimum number of electronic components for a sea-going instrument was less than one, by the mid-1980s our seagoing laboratories would have put any local electronics store to shame. Marine chemistry adopted and adapted the techniques of its land-based siblings, and expanded in directions too numerous to cover in one paper, particularly if we wish also to speculate on where the field will be going. Of necessity, I will not attempt to discuss all of the important new developments in chemical oceanography. Instead, I will examine some examples I feel to be important and with which I have had some experience.

\section{INTERCOMPARISON AND INTERCALIBRATION}

It takes only one deep-water cruise for a beginning oceanographer to realize how vast is the ocean, and how few and far apart his data points. If one is to treat such data, often taken in different parts of the ocean and at different times of the year, as other than an interesting collection of numbers telling us something about the average composition of seawater, one must make some assumptions about the state of the oceans as a system. The starting assumption has usually been that the oceans are in a steady state, more or less. However, we have known almost from the beginning that such was not the case. Seasonal changes have always been obvious. As our remote sensing facilities have improved, the importance of major changes in weather patterns, as, for example, El Niño, has been recognized. The further possibility that we are in a period of major changes in our oceanic systems can only be assessed with data taken as close as possible to simultaneous. We need a snapshot of the oceans as they are now, to be compared to such snapshots taken at various times in the future.

For at least the next years, as it has for the past twenty years, a major part of the world's budget for oceanographic research will be devoted to multinational, multi-ship programs. One must realize that this is an interim period, awaiting the construction of self-reporting buoys which sit out on station and measure all the desired variables. While these buoys are a relatively new development, I first heard them proposed by Fritz Koczy in the early 1960s. Unfortunately, the technology of the time was not equal to the task. Buoys of this general type already exist and are deployed, but as yet they measure only a few of the components of interest to the marine chemist. In time, more components will be added, until finally almost all physical and chemical data will come from moored and free-floating buoys and from satellites. The major problem then will be to devise methods of extracting the required information from the tremendous mass of data accumulating on our computers. I suspect that oceanographers will have something to learn from the data miners used so heavily by market researchers. I would expect that eventually we will have oceanographers whose real medium for research will be the data sets accumulating on the big computers, and who will, like the Gilbert and Sullivan Ruler of the Queen's Navee, stick close to their desks and never go to sea.

However, as long as the data reported is taken by a number of different vessels and run in a number of different laboratories, there must be some assurance that the samples were taken with proper care and analyzed with methods producing comparable results. Some form of intercalibration and intercomparison of methods must be a requirement for any multi-ship operation. I have discussed this matter at greater length in an earlier paper (Wangersky, 2000), so I will only touch on some major points.

The first question to be asked is can we measure the component of interest with a reasonable precision and accuracy in a sample handed to us in a 
bottle? The precision attainable can be measured within a laboratory, but the accuracy requires input from an outside source. The best source would be one which conducted regular intercomparison round robins for those components to be measured in the latest group of multi-national programs. I mention several such sources in my earlier paper. Probably the most useful of such intercomparison efforts were the series run by the International Council for the Exploration of the Seas (ICES), covering a wide variety of compounds of interest to chemical and biological oceanographers (Alzieu et al., 1986).

As most of us expected, the first round of such testing usually demonstrated an unacceptable variability between laboratories (Macaulay, 1974). This proved to be true even for those laboratories which had been running such analyses for years and even for analyses, such as the nutrients, which were largely run on some form of automatic analyzer (Aminot and Kirkwood, 1995). Most laboratories could achieve a useful accuracy fairly quickly. However, it should be pointed out that such accuracy, once achieved, is not a permanent acquisition. Particularly in academic laboratories, run on grant monies, analysts are not permanent fixtures, and the quality of the analyses needs to be re-evaluated at frequent intervals. Funding such intercomparison projects is not easy; no granting panel wishes to take funds away from areas of experimental science in order to fund what they see as an unending responsibility, even if that responsibility is vital to the health of the field. Research museums and culture collections, important though they may be to the experimentalist, are typically maintained by volunteer labour and odd bits of spare time. Intercomparison programs can be set up in much the same way if they are to be run once or twice, perhaps during the lifetime of a major international project. Several such programs, for $\mathrm{fCO}_{2}$ (Tilbrook et al., 2000), DOC (Sharp et al., 2002), and dissolved iron (Bowie et al., 2003), have been run in recent years. It is not likely that these programs will be continuing events. The best hope we have for the continuation and expansion of such programs lies with ICES.

With some caveats, then, we will accept that we are able to determine many of the constituents of interest at concentrations we believe to be typical in seawater if the sample is presented to us in a bottle. I say "we believe to be typical" because in my working lifetime I have seen the "accepted values" for some materials drop faster than the Stock Market on a Gloomy Monday. The "typical" values were typical of the degree of contamination we introduced with our sampling methods (Gordon and Keizer, 1974; Betzer and Pilson, 1975); introduction of more careful sampling methods has resulted in lower accepted values for many trace materials.

Measuring the concentration of materials presented to the analyst in a sample bottle is only part of the problem; the accuracy and precision of the whole process, from sampling to analysis, ideally should be known. There are good reasons why we will never reach the desired degree of certainty in our observations, using our present methods of analysis. In order to make intercomparisons between the sampling and analysis systems as a whole, we would require that the research vessels involved in the intercomparisons draw samples simultaneously from a homogeneous body of water. It is difficult to imagine where one would find a body of water large enough and homogeneous enough for such an exercise, given any reasonably large international program; certainly much recent work has suggested that patchiness in many attributes and at many scales extends throughout the water column (Lehman and Scavia, 1982; Atkinson et al., 1987; Owen, 1989; Kahru et al., 1990; Nero et al., 1990; Duarte and Vaqué, 1992; Taylor and Howes, 1994). At least at this time it does not seem likely that we will be able to separate variability due to the sampling method from that inherent in the universe sampled, as long as we are limited to taking samples at discrete intervals in time and space.

Fortunately, for at least some materials there is the possibility of avoiding the problems inherent in discrete sampling. The remedy lies in the use of probes furnishing a continuous record of the components of interest. Such probes do supply the possibility for checking against a standard, as well as for simultaneous testing. At this time such probes exist for physical and electrochemical properties, such as temperature, conductivity, and total alkalinity (Watanabe et al., 2004), for a few metal ions, such as iron (Bowie et al., 2003), manganese (Klinkhammer et al., 1997), and mercury(II) (Ono and Togashi, 2004), and for the anions nitrate, bromide, and bisulfide (Johnson and Coletti, 2002). Certainly more such probes will be developed; with their use we will begin to understand the limitations placed on our analytical methods by the scales of variability in the oceans.

I have little doubt that oceanography must develop in this direction. Really useful information on the 
current state of the oceans can only come from a much greater density of sampling than we now can manage. Some sort of network of remote buoys, reporting by radio, must eventually be established. I would expect that the typical oceanographic vessel of the future would be a highly sophisticated buoy tender, able to maintain and repair these data stations. How much of the sampling for biological materials can be taken over by machine methods is undetermined. Biological, and to some extent, chemical sampling by such installations is biased because any structure put into the ocean becomes a point of interest for the organisms present, and a surface upon which to attach and grow, as well as a feeding station for larger organisms. That is, after all, the reason why we construct artificial reefs for the enjoyment of the sport fisherman.

\section{THE CONTINUITY PRINCIPLE}

Our beginning assumptions in working up our data must be that the oceans are in something close to a steady state at least over the period covered by our sampling, and that between two sampling points the value of the variable measured will be a smooth function of the difference between the values measured at those points. That is, unless we have good reason to believe it is not. The usefulness of this principle is demonstrated by the way it has led to our understanding of the major features of the oceanic circulation.

However, there have always been data points which did not fit this general pattern. Given the uncertainties involved in sampling and data collection on the relatively small vessels used in the early days of oceanography, as well as the sparseness of the outlying points, the tendency was to regard these points as simple errors, and to leave them out of the subsequent workup of the data. It was not until the advent of the continuously recording conductivity and temperature devices and the satellite data on surface temperatures that the possibility of the inclusion of water masses with sharply discontinuous boundaries within larger, more uniform regions was fully accepted. The presence of these eddies did much to explain how the anomalous data points could have arisen; their presence also suggested that the working oceanographer should have satellite data on his area of interest before he begins to lay out station patterns (Brundage and Dugan, 1985; Ahlnés et al., 1987).
In the case of the surface eddies, the satellite data will at least keep him aware of the present position of existent eddies; he will have to rely on information within the data set itself to warn him of the presence of discrete lenses of water at depth, bearing a salinity and temperature signature different from that of the surrounding water mass. In the North Atlantic such lenses are formed from Mediterranean Bottom Water, hence the name "meddies". Lenses of this sort have been shown to maintain their integrity for two years, and to cross the Atlantic at least as far west as Bermuda. Since these eddies can have a structure, chemistry, and biology differing sharply from the surrounding water mass (Chernyakova and Borodkin, 1988), sampling done in the eddy cannot simply be averaged into the water mass values. The presence of such eddies, at the surface and at depth, means that our simple continuity model is no longer sufficient to describe the distribution of oceanic properties; if we wish to understand the transport of organisms and of some chemical entities, we must include these discontinuous regions in our models (Salihoglu et al., 1990).

The interpretation of cruise data, and even more the interpretation of data from free-floating and anchored buoys will require close cooperation between the physical oceanographers and the chemists and biologists. The development of the CTD allowed the physical oceanographer to cut loose from the other oceanographic disciplines; he no longer needed a shore laboratory to furnish the salinity data that was the foundation of much of his work. However, extracting the motions of the water masses out of the mountains of data which will accumulate from the buoys is a task already approximating the cleaning of the Augean stables. This is a task which must eventually be turned over to the computers; I would expect this to be a task with a high priority.

Along with these larger areas of differing properties, there are smaller discontinuities which can become important under particular circumstances. One of these can result from the activities of the phytoplankton themselves. While we tend to think of the distribution of phytoplankton as being determined by growth and predation rates, along with turbulence in the water column, the dinoflagellates possess enough mobility to station themselves as a thin sheet at a preferred depth. My first exposure to this phenomenon occurred off the African coast on the Afram cruise of the University of Rhode Island vessel the R.V. Trident in 1963. Early one morning 
we were passing through an extensive dinoflagellate bloom which had turned the water bright red. I noticed, however, that the ship's propellers were sending blue water to the surface. Two hours later, when the sun was more nearly overhead, the surface water was blue, but the ship's propellers were sending up the bright red water of the dinoflagellate bloom. A standard surface phytoplankton tow taken at either time would have produced a biased estimate of the actual population, and any estimate of the primary productivity would require a knowledge of the thickness of the bloom layer and its areal extent.

That this was not a unique phenomenon was shown by Bjørnsen and Nielsen (1991), who found a $1 \mathrm{~m}$ thick bloom of Gyrodinium aureolum at the pycnocline. This bloom layer contained more chlorophyll than was present in all the rest of the water column. Given our normal methods of taking plankton tows, this layer would probably have been missed completely or drastically overrepresented.

Non-living particulate matter can also display strongly discontinuous distributions. On the Hudson 70 expedition around the Americas I was able to sample for particulate organic carbon (POC) on a line down the length of the South Atlantic and from $62^{\circ} 55.8^{\prime} \mathrm{S}$ to $54^{\circ} 25^{\prime} \mathrm{N}$, or just before we bumped into Alaska, along the $150^{\text {th }}$ meridian in the Pacific. Because we had access to a rosette sampler with an integral CTD, as well as to a depth recorder which showed us just where our rosette was, we were able to take our samples from selected water masses. We made sure at least one and often two samples were taken from the Antarctic Intermediate Water Mass. This water mass generally carried a POC load higher than the waters just above and below, all the way from the region where it upwelled, at $60^{\circ} \mathrm{S}$, to the Equator (Wangersky, 1976).

This was possibly the earliest date at which I could have carried out this research; the coupled rosette and CTD was what now would be called an Alpha model, not ready for prime time, and traveled with its own nanny. Between stations it could usually be found in a myriad of small pieces on the winch room floor. It was always up and running by station time, even on New Year's Day.

Along with the values typical of their water masses, we found the occasional anomalously high value. While the percentage of such values was small, around 7\%, when something over 800 samples are run the number of instances becomes respectable. The percentage of high values was not too far from the $5 \%$ I had found in an experiment in which I had taken samples in groups of six at each of a series of depths (Wangersky, 1974). Anomalous high values did not appear in a series of similar experiments carried out in the Sargasso Sea (Gordon et al., 1979). On the other hand, if such high values are biological in origin, the Sargasso Sea would not be the best place to look for them.

One place where we might expect to find accumulations of particles might be at density interfaces; divers have reported such "curtains" or "veils" of particles many times but of course, such things do not appear completely real until someone measures or counts them (Zutić and Legović, 1987; Henneke and De Lange, 1990; MacIntyre et al., 1995; Ahel et al., 1996). Observation and capture by divers is necessarily limited to surface waters. Since both the curtains or veils of particles and the possible local bundles of particulate matter could be expected to occupy a rather thin slice of the water column, some method for finding them involving continuous recording was obviously necessary. Transmissometers (Vangriesheim et al., 1992; Bishop, 1999), backscatter (Johnson and Wangersky, 1985; Kitchen and Zaneveld, 1990; Yu et al., 2002), and holography (Carder et al., 1982) have been used.

An advantage in the use of the transmissometer is that there is a good deal of transmissometer data already available (Bishop, 1986), while backscatter and holography are relative newcomers in the field. I do not doubt that properly calibrated transmissometers can supply a reasonable estimate of the mass of particulate matter in the water column; however, we are usually interested both in the mass and in the size distribution of that mass. Transmissometers require that a portion of the water pass between a light source and some photoreceptor. Many of the larger particles in sea water are fragile, to the point where they can be broken up by the water currents induced by feeding euphausiids (Goldthwait et al., 2004). For this reason, we chose to use optical backscatter as our means of detecting above-average areas of particles, with photography as our means of particle identification. The region illuminated by our LED light source and scanned by our photodiode was about $26 \mathrm{~cm}$ from the instrument itself.

Our original backscatter instrument was designed to be used from ships of opportunity, many of which did not have winches capable of sending power down or receiving data up the cable. The backscatter data was recorded on magnetic tape and read, usually, after the cruise. The computers of the 
time which were affordable to the typical researcher would not have been capable of handling the flood of data from a truly online system. If I were designing such a system today, it would be online, and the data handling and presentation would all be done by the software.

The distribution of particulate matter in the water column was much as we expected, with regions higher in concentration occupying very narrow depth ranges. What we did not expect was the great variability with time. Two casts taken as soon as possible in succession could display quite different particle distributions. While estimating the mass of particles in the water column at a particular point and time might well be possible, extending this estimation to any area of reasonable size should require fairly large limits of error.

What do we gain or lose by looking at the scale of discontinuities? First of all, if our interest is in the major features of the oceans we can probably get along with the older assumption of continuity between sampling points. Second, if we wish to look at the oceans in greater detail, we must expect to find discrete areas with properties different from the surrounding water mass. How many of these we find, and of what nature, may depend on the fineness of our sampling grid. The PEX86 expedition, involving fourteen ships, attempted to determine the dimensions of patchiness in the Baltic spring bloom. This turned out to be below the resolution of a 2mile grid (Kahru et al., 1990). In the long run, the decision on the fineness of the sampling grid will probably come from a compromise between heart's desire, computer capability for data handling, and economics.

We should also not forget that when we introduce data-taking buoys into the ocean we are adding to the neighborhood something rather new. How the local inhabitants react to the intrusion may be a study in itself.

\section{DISCONTINUITIES IN TIME}

While we oceanographers have benefited greatly from the introduction of the newer research vessels, we have had to pay a price for their greatly increased capabilities and comforts. The diverse interests of the larger complement of scientists taking part in any one cruise, as well as the requirements of the international programs undertaken, have greatly increased the lead time and the planning required for any extended stay at sea. When last I was involved in considering whether I would need sea time, a two-year lead time was required. One result of the added rigidity in cruise planning is a decrease in the ability to take advantage of special circumstances encountered on the cruise. There are few opportunities to stop by the island of Serendip these days.

As a result, much of the information we have on discontinuities in time come from anecdotal notes, model studies in confined universes, and a few projects aimed directly at happenings over extended time spans. In this case, by "extended" I mean over periods of weeks or months; on most cruises, stays in a given area are likely to be measured in hours or days. If one happens to witness the inception of a process, one is usually far away during the development and climax. In our process through time, as in our process through oceanic space, we like to think the ocean is in a steady - not state, but movement through time. Thus, if we are in a spring bloom here today, tomorrow we will be somewhere else, but still in a spring bloom, one day further along. We know this is not strictly true, but given the vastness of the ocean and the relatively slow speed of our vessels, in a larger sense it is not far off the mark.

Since so many of us were trained in oceanographic institutes situated in the temperate zones, we have the major features of the spring phytoplankton blooms firmly in mind: a gradual accumulation of nutrients in the surface waters, due to regeneration from organic materials, deeper mixing due to winter storms and cooling of the surface layer, and a restraint on photosynthesis from shorter day length and heavier cloud cover. Once the day length and sunshine are favorable for phytoplankton reproduction, the local population grows to a maximum, then crashes. However, it crashes, not to the winter level, but to a level sustainable by regeneration taking place in the surface layer. If the system were left with no further disturbance, we would expect to see a decrease in this growth rate supported by regeneration, as some of the nutrients are transported into deeper water with the particulate matter.

In 1988 a group of graduate students in the Department of Oceanography at Dalhousie (Brad Moran, Bob Pett, Dave Slauenwhite, and Xianliang Zhou) ran just that experiment in the tower tank at Dalhousie; I was associated with the project as faculty advisor (some faculty member had to be involved, in case anything went seriously wrong). The seawater in the tank was bubbled vigorously and then illuminated from above. After a thermocline had been 
established, a culture of Chaetoceros gracilis was introduced into the surface layer. Six days later the culture took off, and followed the growth pattern typical of a spring phytoplankton bloom. We were not able to follow happenings after the crash as long as we might have wished because the tank, like the oceanographic vessels, was too closely scheduled. This work is described in an invited lecture (Wangersky et al., 1989), and in further detail in a series of papers (Moran and Moore, 1988; Zhou et al., 1989; Slauenwhite and Wangersky, 1991).

Certainly, in the temperate and boreal zones the spring bloom is the major pulse of productivity in the oceans. However, in the tropics and in all of the oceans after the initial spring pulse, any source of agitation serving to mix nutrient-bearing water into the surface layers can serve to initiate small local blooms. These blooms are seldom reported, since an oceanographic vessel in a local storm does not usually have the time to hang around for the several days required for the appearance of the bloom. In recent years, however, this phenomenon has been remarked upon in a number of papers (Abbott et al., 1990; Nömmann et al., 1991; Chang et al., 1996; Moline and Prézelin, 1996; Yin et al., 1997). as Goldman (1993) has pointed out, such blooms can amount to an appreciable fraction of the yearly productivity. I discussed some of the consequences of such blooms in an earlier paper (Wangersky, 1983).

A mathematical model has been constructed (Sakshaug et al., 1991) showing how various wind speeds, resulting in different depths for the mixed layer, can either enhance or knock back a plankton bloom. Even without a model, it is easy to see how the frequency as well as the wind strength can affect bloom development. If storms come too often the phytoplankton will continually be mixed down, with some of the population ending below the optimum light level; if the interval between mixing events is too long, the population may be in its crash phase, with few organisms ready to take advantage of the nutrients being mixed upward. The greatest productivity for an area would occur with mixing events about two-thirds of the way up the phytoplankton growth curve. For our tower tank experiment, that would be between three and four days after the population had started to increase, or perhaps a week after the addition of the phytoplankton culture. One might consider that in any given region the phytoplankton species whose growth potential most nearly matched the local storm frequency might be favored during the spring and summer months.
In a year with an especially favorable sequence of storms there should be extra food available for the juveniles of many fish species. Sutcliffe (1972) showed a correlation between rainfall records for the St. Lawrence region and fish landings in southern Nova Scotia. The correlations were lagged by the number of years required for the fish to reach marketable size. Sutcliffe thought the reason for the correlation was extra nutrients washed into the St. Lawrence estuary by the excess rainfall; given the times and distances involved, I think it more likely the extra growth might be better explained by the mixing of the surface layers by the storm winds.

This storm mixing will certainly appear in the data from our buoys, providing our regional coverage is dense enough. Even if it is not, this sort of information should be available from satellites. Furthermore, satellites should be able to delineate the area covered by the upwardly mixed water and by any resulting bloom. What will determine the degree to which we are successful in measuring the productivity resulting from these blooms will be the detail we are willing or able to extract from our satellite data.

A more difficult problem will be keeping track of the undersea storms and the movements of sediment accompanying them. These storms can result from windstorms (Gardner and Sullivan, 1981; Klein, 1987; Islay et al., 1990), from earthquakes (Itou et al., 2000), or from causes still unknown (Woodgate and Fahrbach, 1999). At this time it is difficult to see how such undersea storms can be detected and their extent and duration known. My best guess at this time would be the use of something akin to sonar; the problems involved in powering such a device in the deep ocean are considerable. Along with the movement of sediment, there is a freeing of interstitial water and a displacement of biological materials. A certain amount of sorting must accompany such movement, with the lighter particles being transported farther from the source, thereby adding one more complication to the already complex nature of the marine sediment.

I might seem to be slighting the use of satellites, our major source of information on discontinuities in both space and time. A proper discussion of the immense literature which has developed around this technique would require a full paper in itself. I would not be the proper person to write such a paper; I have not worked with this technique, and I am not fully aware of its possibilities and limitations. Certainly one of the limitations must be the relatively few quantities which can be measured. 
Good data on ocean surface temperatures are now available; if assumptions are made about the temperature structure of the subsurface waters, changes in surface temperatures due to wind events could permit estimates of the depth of mixing brought about by these events.

Changes in the colour of the surface waters, brought about by growth and decay of the phytoplankton population, would give us a better estimate of the primary productivity of the oceans than we can obtain from the relatively sparse sampling patterns we can occupy from oceanographic vessels. Unfortunately, at least to date wherever we have both satellite data and ground truth the relationship between the two data sets has been too variable to permit any but the most general conclusions. Some of the variability is certainly due to the presence of coloured dissolved organic matter, and possibly some to particulate matter. These difficulties should eventually be overcome.

What cannot be overcome are the limitation of the measurements to the surface waters, and the loss of data because of cloud cover. I expect that satellite observations will prove to be a valuable adjunct when used in conjunction with the automated buoy.

\section{CONCLUSION}

In the past, the data of oceanography was very sparse, and much of it limited to areas adjacent to the major marine stations. With the application of logic and imagination, it was possible to obtain a reasonably consistent picture of the major features of the oceanic current systems. As our methods and equipment became more sophisticated, it became obvious that we had missed many of the details. I think we are now in a position where we know we must extend our sampling grid, in both space and time, beyond anything we can hope to achieve with our present sampling methods. The self-reporting sampling buoy seems the logical direction for future research, at least in the physical and chemical aspects of oceanography. How deeply we delve into details will be determined as much by economics as by science, since development and maintenance of such buoys will not be inexpensive, and it is an old oceanographic maxim that anything you put over the side of a ship you must expect to lose, sooner or later. However, much as I have enjoyed a lifetime of going down to the sea in ships, I must really concede that it is time to give up this piecemeal way of data gathering.

\section{ACKNOWLEDGMENTS}

The writing of this paper was funded completely by me. The fifty-plus years of oceanography leading up to it were funded at various times and in various places by the U. S. Atomic Energy Commission, U. S. Office of Naval Research, U. S. National Science Foundation, Canadian National Research Council, Canadian Natural Sciences and Engineering Research Council and the J. S. Guggenheim Foundation.

\section{REFERENCES}

Abbott, M.R., K.H. Brink, C.R. Booth, D. Blasco, L.A. Codispoti, P.P. Niiler and S.R. Ramp. - 1990. Observations of phytoplankton and nutrients from a Lagrangian drifter off northern California, J. geophys. Res., 95: 9393-9409.

Ahel, M., R.G. Barlow and R.E.C. Mantoura. - 1996. Effect of salinity gradients on the distribution of phytoplankton pigments in a stratified estuary. Mar. Ecol. Prog. Ser., 143: 289-295.

Ahlnés, K., T.C. Royer and T.H. George. - 1987. Multiple dipole eddies in the Alaska Coastal Current detected with Landsat thematic mapper data. J. geophys. Res., 92: 13,041-13,047.

Alzieu, C., J.M. Bewers and J.C. Duinker. - 1986. Administrative summary report of the ICES fifth round intercalibration for trace metals in seawater. ICES coop. Res. Rept., 136: 1-4.

Aminot, A., and D. Kirkwood. - 1995. Report on the results of the fifth ICES Intercomparison Exercise for nutrients in sea water. ICES coop. Res. Rept., 213: 1-79.

Atkinson, M.J., T. Berman, B.R. Allanson and J. Imberger. - 1987. Fine-scale oxygen variability in a stratified estuary: patchiness in aquatic environments. Mar. Ecol. Prog. Ser., 36: 1-10.

Betzer, P.R. and M.E. Q. Pilson. - 1975. The effect of corroded hydrographic wire on particulate iron concentrations in seawater. Deep Sea Res., 22: 117-120.

Bishop, J.K.B. - 1986. The correction and suspended particulate matter calibration of Sea Tech transmissometer data. Deep Sea Res., 33: 121-134.

Bishop, J.K.B. -1999. Transmissometer measurement of POC. Deep Sea Res., 46: 353-369.

Bjørnsen, P.K. and T.G. Nielsen. - 1991. Decimeter scale heterogeneity in the plankton during a pycnocline bloom of Gyrodinium aureolum. Mar. Ecol. Prog. Ser., 73: 263-267.

Bowie, A.R., E.P. Achterberg, S. Blain, M. Boye, P.L. Croot, H.J.W. de Baar, P. Laan, G. Sarthou and P.J. Worsfold. - 2003. Shipboard analytical intercomparison of dissolved iron in surface waters along a north-south transect of the Atlantic Ocean. Mar. Chem., 84: 19-34.

Brown, N.L. - 1964. An in situ salinometer for use in the deep oceans. Instr. Soc. Am. Reprint No. 812: 12-64.

Brown, N.L. and B.V. Hamon. - 1961. An inductive salinometer. Deep Sea Res. 8: 65-70.

Brundage, W.L. and J.P. Dugan. - 1986. Observations of an anticyclonic eddy of $18^{\circ} \mathrm{C}$ water in the Sargasso Sea. J. phys. Oceanogr., 16: 717-727.

Carder, K.L., R.G. Steward, and P.R. Betzer. - 1982. In situ holographic measurements of the sizes and settling rates of oceanic particulates. J. geophys. Res., 87: 5681-5685.

Chang, J., C-C. Chung and G-C. Gong. - 1996. Influences of cyclones on chlorophyll a concentration and Synechococcus abundance in a subtropical western Pacific coastal ecosystem. Mar. Ecol. Prog. Ser., 140: 199-205.

Chernyakova, A.M. and S.O. Borodkin. - 1988. Hydrochemical structure of an eddy of the California Current. Oceanology, 28: 590-594.

Duarte, C.M. and D. Vaqué. - 1992. Scale dependence of bacterioplankton patchiness. Mar. Ecol. Prog. Ser., 84: 95-100.

Gardner, W.D. and L.G. Sullivan. - 1981. Benthic storms: temporal variability in a deep-ocean nepheloid layer. Science, 213: 329-331. 
Goldman, J.C. - 1993. Potential role of large oceanic diatoms in new primary production. Deep Sea Res., 40: 159-168.

Goldthwaite, S., J. Yen, J. Brown and A. Alldredge. - 2004. Quantification of marine snow fragmentation by swimming euphausiids. Limnol. Oceanogr., 49: 940-952.

Gordon, D.C. Jr. and P.D. Keizer. - 1974. Estimation of petroleum hydrocarbons in seawater by fluorescence spectroscopy: improved sampling and analytical methods. Fish. Mar. Service Tech. Rpt. No. 481: 1-24.

Gordon, D.C. Jr., P.J. Wangersky, and RW. Sheldon. - 1979. Detailed observations on the distribution and composition of particulate organic material at two stations in the Sargasso Sea. Deep Sea Res., 26: 183-192.

Grasshoff, K., M. Ehrhardt and K. Kremling. - 1983. Methods of Seawater Analysis, $2^{\text {nd }}$ ed., Verlag Chemie GmbH, Deerfield Beach, Florida.

Henneke, E., and G.J. De Lange. - 1990. The distribution of DOC and POC in the water column and brines of the Tyro and Bannock Basins. Mar. Chem., 31: 113-123.

Isley, A.E., R.D. Pillsbury, and E.P. Laine. - 1990. The genesis and character of benthic turbid events, Northern Hatteras Abyssal Plain. Deep Sea Res., 37: 1099-1119.

Itou, M., I. Matsumura and S. Noriki. - 2000. A large flux of particulate matter in the deep Japan Trench observed just after the 1994 Sanriku-Oki earthquake. Deep Sea Res., 47: 1987-1998.

Johnson, B.D. and P.J. Wangersky. - 1985. A recording backward scattering meter and camera system for examination of the distribution and morphology of macroaggregates. Deep Sea Res., 32: $1143-1150$

Johnson, K.S. and L.J. Coletti. - 2002. In situ ultraviolet spectrophotometry for high resolution and long-term monitoring of nitrate, bromide and bisulfide in the ocean. Deep Sea Research Part I . Oceanogr. Res., 49: 1291-1305.

Kahru, M., J.-M. Leppänen, S. Nômmann, U. Passow, L. Postel and S. Schulz. - 1990. Spatio-temporal mosaic of the phytoplankton spring bloom in the open Baltic Sea in 1986. Mar. Ecol. Prog. Ser., 66: 301-309.

Kitchen, J.C. and J.R.V. Zaneveld. - 1990. On the noncorrelation of the vertical structure of light scattering and chlorophyll $a$ in Case I waters. J. geophys. Res., 95: 20,237-20,246.

Klein, H. - 1987. Benthic storms, vortices, and particle dispersion in the deep west European basin. Dt. hydrogr. Z., 40: 87-102.

Klinkhammer, G.P., C.S. Chin, C. Wilson, M.D. Rudnicki and C.R. German. - 1997. Distributions of dissolved manganese and fluorescent dissolved organic matter in the Columbia River estuary and plume as determined by in situ measurement. Mar. Chem., 56: 1-14.

Lehman, J.T. and D. Scavia. - 1982. Microscale patchiness of nutrients in plankton communities. Science, 216: 729-730.

Macauley, I.D. - 1974. Pilot intercalibration I: Trace metals in freshwater and seawater. BIO Rept. Ser. BI-R-74-1: 1-8.

MacIntyre, S., A.L. Alldredge and C.C. Gottschalk. - 1995. Accumulation of marine snow at density discontinuities in the water column. Limnol. Oceanogr., 40: 449-468.

Moline, M.A. and B.B. Prézelin. - 1996. Long-term monitoring and analyses of physical factors regulating variability in coastal Antarctic phytoplankton biomass, in situ productivity and taxonomic composition over subseasonal, seasonal and interannual time scales. Mar. Ecol. Prog. Ser., 145: 143-160.

Moran, S.B. and R.M. Moore - 1988. Evidence from microcosm studies for biological removal of dissolved aluminium from sea water. Nature, Lond., 335: 705-708.

Nero, R.W., J.J. Magnuson, S.B. Brandt, T.K. Stanton, and J.M. Jech. - 1990. Finescale biological patchiness of $70 \mathrm{kHz}$ acoustic scattering at the edge of the Gulf Stream - Echofront 85. Deep Sea Res., 37: 999-1016.

Nömmann, S., J. Sildam, T. Nôges and M. Kahru. - 1991. Plankton distribution during a coastal upwelling event off Hiiumaa, Baltic Sea: impact of short-term flow field variability. Conti- nent. Shelf Res., 11: 95-108.

Ono, A. and H. Togashi. - 2004. Highly selective oligonucleotidebased sensor for mercury(II) in aqueous solutions. Angew. Chem. Int. Ed. 43: 4300-4302.

Owen, R.W. - 1989. Microscale and finescale variations of small plankton in coastal and pelagic environments. J. mar. Res., 47: 197-240.

Sakshaug, E., D. Slagstad and O. Holm-Hansen. - 1991. Factors controlling the development of phytoplankton blooms in the Antarctic Ocean - a mathematical model. Mar. Chem., 35: 259-271.

Salihoglu, I., C. Saydam, Ö. Bastürk, K. Yilmaz, D. Göçmen, E. Hatipoglu, and A. Yilmaz. - 1990. Transport and distribution of nutrients and chlorophyll- $a$ by mesoscale eddies in the northeastern Mediterranean. Mar. Chem., 29: 375-390.

Sharp, J.H., C.A. Carlson, E.T. Peltzer, D.M. Castle-Ward, K.B. Savidge and K.R. Rinker. - 2002. Final dissolved organic carbon broad community intercalibration and preliminary use of DOC reference materials. Mar. Chem., 77: 239-253.

Slauenwhite, D.E. and P.J. Wangersky. - 1991. Behaviour of copper and cadmium during a phytoplankton bloom: a mesocosm experiment. Mar. Chem., 32: 37-50.

Sutcliffe, W.H. Jr. - 1972. Some relations of land drainage, nutrients, particulate material, and fish catch in two eastern Canadian bays. J. Fish. Res. Bd. Can., 29: 357-362.

Taylor, C.D. and B.L. Howes. - 1994. Effect of sampling frequency on measurements of seasonal primary production and oxygen status in near-shore coastal ecosystems. Mar. Ecol. Prog. Ser., 108: 193-203.

Tilbrook, B., P. Towler, H.Y. Inoue, M. Ishii, G. Shaffer, R. Torres Saavedra, E. Ohtaki, E. Yamashita, A. Poisson, C. Brunet, B. Schauer, C. Goyer and G. Eischeid. - 2000. The international at-sea intercomparison of fCO2 systems during the R/V Meteor Cruise 36/1 in the North Atlantic Ocean. Mar. Chem. 72: $171-192$.

Vangriesheim, A., J.P. Gouillou and L. Prieur. - 1992. A deep-sea nephelometer to detect Bottom and Intermediate Nepheloid layers. Deep Sea Res., 39: 1403-1416.

Wangersky, P.J. - 1974. Particulate organic carbon: sampling variability. Limnol. Oceanogr., 19: 980-984.

Wangersky, P.J. - 1976. Particulate organic carbon in the Atlantic and Pacific Oceans. Deep Sea Res., 23: 457-465.

Wangersky, P.J. - 1983. The cycle of organic carbon in the ocean Atti $5^{\circ}$ Congr. A.I.O.L., 5: 29-100.

Wangersky, P.J. - 2000. Intercomparisons and intercalibrations. In: The Handbook of Environmental Chemistry, Vol. 5-D, Marine Chemistry, pp. 167-191.

Wangersky, P.J., S.B. Moran, R.J. Pett, D.E. Slauenwhite and X. Zhou. - 1989. Biological control of trace metal residence times: an experimental approach. Mar. Chem., 28: 215-226.

Watanabe, A., H. Kayanne, K. Nozaki, K. Kato, A. Negishi, S. Kudo, H. Kimoto, M. Tsuda and A.G. Dickson. - 2004. A rapid, precise potentiometric determination of total alkalinity in seawater by a newly developed flow-through analyzer designed for coastal regions. Mar. Chem. 85: 75-87

Woodgate, R.A. and E. Fahrbach. - 1999. Benthic storms in the Greenland sea. Deep Sea Res., 46: 2109-2127.

Yin, K., R.H. Goldblatt, P.J. Harrison, M.A. St. John, P.J. Clifford and R.J. Beamish. - 1997. Importance of wind and river discharge in influencing nutrient dynamics and phytoplankton production in summer in the central Strait of Georgia. Mar. Ecol. Prog. Ser., 161: 173-183.

Yu, X., T. Dickey, J. Bellingham, D. Manova and K. Streitlien. 2002. The application of autonomous underwater vehicles for interdisciplinary measurements in Massachusetts and Cape Cod Bays. Continent. Shelf Res., 22: 2225-2245.

Zutić, V. and T. Legović. - 1987. A film of organic matter at the freshwater-seawater interface of an estuary. Nature, 328: 613-614. 